\title{
O impacto da infecção por Chlamydia em populações indígenas da Amazônia brasileira
}

\author{
Dissemination of Chlamydia infection \\ among native Indian groups of the Brazilian \\ Amazon region
}

Marluísa de Oliveira Guimarães Ishak 1

Ricardo Ishak 1

\footnotetext{
${ }^{1}$ Laboratório de Virologia, Departamento de Patologia, Centro de Ciências Biológicas, Universidade Federal do Pará. C. P. 13005, Belém, PA 66049-970, Brasil. rishak@canal13.com.br
}

\begin{abstract}
Knowledge is limited on the spread of bacteria from genus Chlamydia in Brazil. This study included a sero-epidemiological survey of 2,086 samples from native Indian populations of the Brazilian Amazon region. Sera were screened using indirect immunofluorescence assay for detection of antibodies to C. trachomatis serotype L2, followed by microimmunofluorescence assay using fifteen $\mathrm{C}$. trachomatis and C. pneumoniae serotypes as antigen substrates. Antibody prevalence was $48.6 \%$, but there was a large prevalence range among the groups, including those that had never been challenged with the bacteria, as well as those in which almost all individuals had been infected. Titration of IgG antibodies and detection of specific IgM in high-titer samples showed the persistence of Chlamydia in $6.1 \%$ of the reactive individuals, who probably play an important role as reservoirs for dissemination of the bacteria. Specific seroreactivity to C. trachomatis showed the presence of serotypes $A, B, B a, D, E, G, H, I$, and $L 1$ in the geographic area surveyed. Furthermore, the survey showed that C. pneumoniae was also infecting these individuals. Both species may be involved in a significant human disease burden that merits further clarification.
\end{abstract}

Key words Epidemiology Descriptive; Chlamydia; South American Indians

Resumo A disseminação das bactérias do gênero Chlamydia no Brasil, inclusive na região Amazônica, é pouco conhecida. Este estudo soroepidemiológico incluiu 2.086 amostras de soro de populações indígenas da Amazônia brasileira, empregando metodologia de triagem pela imunofluorescência indireta para pesquisa de anticorpos. Usou-se o sorotipo L2 da C. trachomatis como substrato; a seguir, para os quinze sorotipos de C. trachomatis e para a C. pneumoniae, discriminou-se a sororreatividade pela microimunofluorescência específica. A prevalência média de anticorpos para Chlamydia foi de 48,6\%. Sua variação entre as comunidades indicou as que não tiveram contato com as bactérias e aquelas em que quase todos os testados tiveram. Por meio da titulação dos anticorpos IgG e a presença de IgM específica nas amostras com títulos altos viu-se que 6,1\% dos infectados persistiam com a infecção, servindo de reservatórios à disseminação das espécies de Chlamydia. Pela resposta à C. trachomatis, evidenciou-se a circulação dos sorotipos $A, B, B_{a}, D, E, G, H$, I e $L_{1}$. Ademais, constatou-se que há C. pneumoniae na região. As duas espécies causariam impacto significativo no hospedeiro humano.

Palavras-chave Epidemiologia Descritiva; Chlamydia; Índios Sul-Americanos 


\section{Introdução}

O presente trabalho descreve a disseminação das espécies Chlamydia trachomatis (e seus sorotipos) e C. pneumoniae por meio da prevalência de anticorpos entre populações indígenas na região da Amazônia brasileira.

As infecções e doenças humanas associadas à bactérias do gênero Chlamydia (C. trachomatis, $C$. pneumoniae e $C$. psittaci) têm sido reconhecidas como problemas graves de saúde coletiva, e estão relacionadas a infecções oculares, como o tracoma; a infecções genitais, como as uretrites não-gonocócicas e cervivites mucopurulentas, que podem evoluir para doença inflamatória pélvica (DIP), gravidez ectópica e infertilidade; e a infecções cardiorrespiratórias, como as pneumonias adquiridas em comunidade (PAC). A Organização Mundial de Saúde calculou a ocorrência de cerca de 89 milhões de novos casos de infecção por este patógeno no ano de 1995 (Peeling \& Brunham, 1996; WHO, 1995). Nos Estados Unidos, estimase o surgimento de cerca de quatro milhões de novos casos anuais de C. trachomatis, com o prejuízo adicional de 50.000 mulheres que se tornam inférteis em decorrência da infecção (Washington et al., 1987). A C. trachomatis é uma bactéria que possui formas bem definidas de transmissão, e a via sexual é provavelmente a mais comum delas, o que a torna uma das mais importantes infecções sexualmente transmissíveis.

A C. pneumoniae tem sido freqüentemente relacionada a quadros clínicos de ateroesclerose e asma (Campbell et al., 1998), além de sua associação como patógeno respiratório comum entre seres humanos. Em demonstração experimental de associação epidemiológica entre a infecção por Chlamydia e a doença cardíaca em seres humanos (Quinn et al., 1996), foi possível evidenciar recentemente a indução de doença cardíaca inflamatória autoimune em resposta à proteína da membrana externa presente nas três espécies de Chlamydia (Bachmaier et al., 1999).

Poucas informações têm sido geradas acerca das infecções pelas bactérias do gênero Chlamydia em nosso país. Sinais de tracoma ativo ou inativo foram encontrados em $33 \%$ dos habitantes da Amazônia mediante trabalho clínico-epidemiológico de Freitas (1976). Em abordagem clínica-laboratorial, a C. trachomatis foi identificada em $51 \%$ de homens com uretrite não-gonocócica no Recife, Pernambuco (Magalhães et al., 1982), da mesma forma que em 30\% de homens em Belém, Pará (Ishak et al., 1993). Estudos de natureza soroepide- miológica, por sua vez, mostram, com clareza, que a infecção por Chlamydia é comum em diferentes grupos populacionais urbanos e não urbanos (Ishak, 2000; Ishak et al., 1988, 1993).

\section{Material e métodos}

\section{Grupos Populacionais Examinados}

Os grupos populacionais indígenas envolvidos no presente trabalho estão listados na Tabela 1 . Foram examinados 2.086 indivíduos - procedentes de 27 comunidades - que apresentavam graus diferenciados de isolamento em relação a comunidades neo brasileiras da Amazônia brasileira.

A informação a respeito de sexo e idade só pôde ser descrita de maneira adequada em dezesseis das comunidades indígenas examinadas. A composição demográfica dos indivíduos foi de 44,5\% (928/2.086) do sexo masculino; entretanto, $15,1 \%(316 / 2.086)$ das pessoas testadas não estavam registradas satisfatoriamente, assim como não havia informações adequadas acerca do sexo dos indivíduos testados (Tabela 1).

As populações indígenas foram oriundas de 27 comunidades, distribuídas nos estados do Maranhão (Urubú-Kaapór e Awa-Guajá), Amapá (Galibí-Uaçá, Palikúr e Waiãpi), Pará (Wayána-Apalaí, Tiriyó, Asuriní do Kuatinemo, Asuriní do Trocará, Arára do Iriri, Arára do Laranjal/ Arára do Kurambê, Araweté, Parakanã, Kayapó - aldeias Aukre, Kubenkokre, Pukany, Kikretum, Kokraimôro, Kararaô e Xikrín do Bacajá Mundurukú e Katwena), Roraima (Yanomámi), Amazonas (Yamamadí) e Rondônia (Cinta-Larga, Suruí e Karitiána).

Convém ressaltar que as tribos Urubú-Kaapór e Wayána-Apalaí foram revisitadas e aparecem com quatro percentuais de prevalência de anticorpos na seção de Resultados - por exemplo, Urubú-Kaapór I e Urubú-Kaapór II -, porém foram contadas como duas comunidades. A união entre os Wayana e os Apalai na mesma aldeia tornou impraticável a separação das duas comunidades. Os Arára do Laranjal e os Arára do Kurambê são duas comunidades, mas aparecem com percentual único de prevalência de anticorpos, uma vez que a separação dos dois grupos por ocasião da coleta levou em conta apenas a perspectiva histórica, já que os dois grupos viviam juntos. 
Tabela 1

Distribuição dos grupos indígenas examinados quanto à presença de anticorpos para Chlamydia, de acordo com a localização, o tronco lingüístico, o ano de coleta da amostra, a estimativa de população e o sexo, na Amazônia brasileira - 1984 a 1995

\begin{tabular}{|c|c|c|c|c|c|c|c|}
\hline \multirow[t]{2}{*}{ Estado/Tribo } & \multirow{2}{*}{$\begin{array}{l}\text { Tronco } \\
\text { Lingüístico }\end{array}$} & \multirow{2}{*}{$\begin{array}{l}\text { Ano da } \\
\text { Coleta }\end{array}$} & \multirow{2}{*}{$\begin{array}{l}\text { População } \\
\text { Estimada }\end{array}$} & \multicolumn{4}{|c|}{ Examinados } \\
\hline & & & & Masc. & Fem. & Ind. & Total \\
\hline \multicolumn{8}{|l|}{ Maranhão } \\
\hline Urubú-Kaapór I & Tupí & 1984 & & 93 & 67 & & 160 \\
\hline Urubú-Kaapór II & Tupí & 1994 & 1.100 & 25 & 22 & & 47 \\
\hline Awa-Guajá & Tupí-Guaraní & 1993 & 230 & 51 & 35 & & 86 \\
\hline \multicolumn{8}{|l|}{ Amapá } \\
\hline Galibí-Uaçá & Karíb & 1988 & 860 & 70 & 70 & 19 & 159 \\
\hline Palikúr & Aruák & 1988 & 561 & 25 & 33 & & 58 \\
\hline Waiãpi & Tupí-Guaraní & 1994 & 295 & 53 & 36 & & 89 \\
\hline \multicolumn{8}{|l|}{ Pará } \\
\hline Wayána-Apalaí I & Karíb & 1983 & 350 & 66 & 49 & 19 & 134 \\
\hline Wayána-Apalaí II & Karíb & 1993 & 233 & 18 & 22 & & 40 \\
\hline Tiriyó & Karíb & 1990 & 383 & 14 & 12 & & 26 \\
\hline Asuriní do Kuatinemo & Tupí & 1984 & 54 & 15 & 26 & & 41 \\
\hline Asuriní do Trocará & Tupí & 1984 & 150 & 11 & 10 & & 21 \\
\hline Arára do Iriri & Karíb & 1991 & 60 & 16 & 11 & 1 & 28 \\
\hline $\begin{array}{l}\text { Arára do Laranjal/ } \\
\text { Kurambê }\end{array}$ & Karíb & 1991 & 73 & 26 & 21 & & 47 \\
\hline Araweté & Tupí & 1983 & 139 & 41 & 40 & & 81 \\
\hline Parakanã & Tupí & 1995 & 140 & - & - & 42 & 42 \\
\hline Aukre & Jê & 1989 & $\star 2.100$ & 11 & 1 & 4 & 16 \\
\hline Kubenkokre & Jê & 1990 & $\star 2.100$ & - & - & 91 & 91 \\
\hline Pukany & Jê & & $\star 2.100$ & - & - & 50 & 50 \\
\hline Kikretum & Jê & & $\star 2.100$ & - & - & 16 & 16 \\
\hline Kokraimôro & Jê & & $\star 2.100$ & 42 & 51 & & 93 \\
\hline Kararaô & Jê & 1986 & $\star 2.100$ & 11 & 12 & 9 & 32 \\
\hline Xikrín-Bacajá & Jê & 1995 & $\star 2.100$ & - & - & & 54 \\
\hline Mundurukú & Tupí & 1988 & 3.000 & 63 & 72 & 12 & 147 \\
\hline Katwena & Carib & 1995 & 705 & 93 & 84 & & 177 \\
\hline \multicolumn{8}{|l|}{ Roraima } \\
\hline Yanomámi & Yanomámi & 1990 & $* \star 10.000$ & 39 & 42 & & 81 \\
\hline \multicolumn{8}{|l|}{ Amazonas } \\
\hline Yamamadí & Arawá & 1986 & 70 & 19 & 17 & & 36 \\
\hline \multicolumn{8}{|l|}{ Rondônia } \\
\hline Cinta-Larga & Tupí & 1987 & 953 & 49 & 39 & 14 & 102 \\
\hline Suruí & Tupí & 1987 & 109 & 30 & 29 & & 59 \\
\hline Karitiána & Arikém & 1986 & 130 & 38 & 35 & & 73 \\
\hline Total & & & 21.695 & 919 & 836 & 331 & 2.086 \\
\hline
\end{tabular}

* Aldeias Kayapó; população do total de aldeias estimada em cerca de 2.100 indivíduos

** Cerca de 150 aldeias, totalizando por volta de 10.000 indivíduos. 


\section{Obtenção das amostras de soro e plasma}

Todos os grupos populacionais envolvidos fizeram parte de um Programa de Assistência à Saúde Indígena, realizado de forma colaborativa entre os Laboratórios de Virologia e de Genética Médica e Humana, do Centro de Ciências Biológicas da Universidade Federal do Pará, e a Fundação Nacional do Índio (FUNAI), que se iniciou em 1983.

Em todas as visitas foi prestado atendimento médico-laboratorial aos indivíduos examinados e coletada uma amostra de sangue por meio de punção venosa para obtenção de soro ou plasma. As amostras foram centrifugadas no local de coleta quando havia disponibilidade, ou em laboratório, para a separação do plasma ou do soro após a coagulação. As coleções de soro e plasma foram mantidas a $-20 \circ \mathrm{C}$, até o momento de uso.

\section{Imunofluorescência indireta (IFI)}

Lâminas comerciais (BioMerieux) impregnadas com o antígeno de C. trachomatis, cepa $\mathrm{L}_{2}$ foram utilizadas como substrato da reação de triagem de anticorpos para o gênero Chlamydia, uma vez que a referida cepa possui antígenos comuns aos demais sorotipos de C. trachomatis, bem como às espécies C. pneumoniae (Campbell et al., 1990; Grayston \& Wang, 1975) e C. psittaci (Treharne et al., 1977).

A metodologia seguiu um padrão já descrito anteriormente (Collier et al., 1972; Ishak et al., 1988, 1993; Richmond \& Caul, 1975). As amostras de soro foram depositadas sobre as lâminas, as quais foram lavadas durante cinco minutos, por três vezes, em solução salina tamponada (PBS), após incubação a 37oC durante 45 minutos em câmara úmida. Em seguida, foi adicionado um conjugado com atividade antiIgG. Depois de nova incubação e novo ciclo de lavagens, as lâminas foram montadas com glicerina tamponada ( $\mathrm{pH} 9,0)$ e a leitura efetuada com objetiva de 40x em um microscópio de imunofluorescência Axiophot, montado com sistema de epi-iluminação.

As amostras de soro ou plasma foram diluídas e testadas inicialmente na diluição de 1:32. As amostras positivas foram diluídas até a diluição de 1:512 e testadas, usando-se um conjugado anti-IgG. As amostras com título $\geq 512$ foram testadas na diluição de 1:8, empregando-se um conjugado anti-IgM. Ambos os conjugados foram previamente titulados e, em todos os testes, foram incluídos controles positivo, negativo e do conjugado, no qual se usou solução salina em lugar da amostra.
A presença de anticorpos IgG em diluições de 1:32 foi usada como indicativo de exposição prévia à bactérias do gênero Chlamydia. Por sua vez, a presença de títulos elevados (>512) na ausência de anticorpos de natureza IgM serviu para indicar infecção persistente por Chlamydia.

\section{Microimunofluorescência (MIF)}

$\mathrm{O}$ antígeno de $C$. pneumoniae e os quinze sorotipos de C. trachomatis (A, B, Ba , C, D, E, F, G, H, I, J, K, $\mathrm{L}_{1}, \mathrm{~L}_{2}$ e $\mathrm{L}_{3}$ ) foram obtidos comercialmente da Washington Research Foundation, Seattle, Washington, Estados Unidos. As lâminas que continham os dezesseis antígenos utilizados no teste foram preparadas no Laboratório de Virologia do Centro de Ciências Biológicas Universidade Federal do Pará. Os testes foram controlados por meio da suspensão de gema de ovo não inoculado para detectar reações inespecíficas contra o substrato que foi utilizado para fixar o antígeno sobre a lâmina e facilitar a visualização do material ao microscópio.

As preparações antigênicas são constituídas de corpúsculos elementares inteiros - obtidos a partir de células HeLa 229 infectadas -, purificados em gradiente de concentração que se apresenta com a superfície intacta e tratados com formalina. Cada preparação contém aproximadamente $10^{9}$ partículas/mL de PBS, tendo $0,02 \%$ de formalina. Às suspensões antigênicas foram acrescidos volumes iguais (aproximadamente $0,1 \mathrm{~mL}$ ) da suspensão da gema de ovo e homogeneizados em Vortex precedendo sempre cada aplicação da suspensão sobre as lâminas.

Cada suspensão antigênica foi depositada sobre as lâminas com o auxílio de uma pena para tinta nanquim (Hunt Artist's Pens 104, no. 9404) - observando-se o uso de uma pena para cada sorotipo -, obedecendo-se a um molde de papel colocado debaixo da lâmina que contém os dezesseis pontos distribuídos em quatro grupos de quatro, afastados por, pelo menos, $5 \mathrm{~mm}$ de distância entre os pontos. Após a secagem da suspensão à temperatura ambiente por um mínimo de 30 minutos, as lâminas foram fixadas em acetona à temperatura ambiente durante quinze minutos e estocadas a $-20 \circ \mathrm{C}$ até o momento de uso.

Dentre as amostras de soro ou plasma que mostraram reatividade no teste de IFI foi selecionada uma amostra de $12 \%$ com o auxílio do programa Epi Info, versão 6.0 (CDC/WHO, 1996), para ser sorotipada por meio da MIF. As amostras foram testadas inicialmente na diluição 1:8 em PBS frente aos dezesseis antígenos. Aquelas 
que mostraram fluorescência clara, nítida e esverdeada frente a qualquer um ou mais sorotipos, foram então tituladas.

O teste seguiu uma metodologia padrão descrita anteriormente (Wang \& Grayston, 1974). As amostras de soro ou plasma diluídas em PBS (diluições seriadas de 1:8 até 1:1.024) foram aplicadas sobre os antígenos com o auxílio de uma alça de platina (níquel-cádmio) da maior para a menor diluição, secando-se a alça em papel absorvente entre a aplicação de duas diluições. As lâminas foram incubadas a $37 \circ \mathrm{C}$ durante 30 minutos em câmara úmida, primeiro, com o soro ou o plasma teste e depois, com o conjugado anti IgG. Ao término de cada uma das incubações, as lâminas foram lavadas quatro vezes em PBS e três vezes em água destilada, tendo sido mergulhadas nos depósitos de vidro de maneira delicada, uma por vez, com o auxílio de pinça plástica. A montagem e leitura foi igual à descrita acima para a IFI.

\section{Métodos estatísticos}

O presente estudo utilizou o conceito clássico para o cálculo de prevalência, indicando o número de pessoas, em um grupo populacional, que possui a característica pesquisada (no caso, a presença de anticorpos para Chlamydia) em dado ponto no tempo (Mausner \& Bahn, 1974).

A seleção das amostras para o teste de MIF foi feita por meio de seleção randômica, usando-se o programa Epi Info, versão 6.0 (CDC/ WHO, 1996).

A significância das diferenças entre as prevalências de anticorpos para Chlamydia nas várias comunidades foi testada mediante o teste binomial para avaliar a diferença entre duas amostras independentes. O nível de significância considerado foi de $95 \%(p<0,05)$. Os cálculos foram efetuados por intermédio do programa Bioestat (Ayres et al., 1998).

\section{Resultados}

Os resultados gerais de prevalência de anticorpos da classe IgG para Chlamydia - baseados em estudos soroepidemiológicos entre as comunidades indígenas testadas no decorrer do presente projeto - estão mostrados, de forma resumida, na Tabela 2.

A prevalência média de anticorpos foi de 48,6\%, destacando-se que os Arára do Iriri não mostraram anticorpos para Chlamydia. Os percentuais de prevalência evidenciaram variação que foi desde prevalências baixas - como entre os Tiriyó (11,5\%), os Asuriní do Trocará (14,3\%),
Tabela 2

Prevalência de anticorpos (lgG) para Chlamydia, freqüência de títulos elevados de IgG ( $\geq 512$ ) e presença de IgM específica, detectados por meio da IFI, em grupos populacionais indígenas da Amazônia brasileira.

\begin{tabular}{|c|c|c|c|c|}
\hline Estado/Tribo & Examinados & $\%$ Positivos & $\% \operatorname{lgG} \geq 512^{\star}$ & $\lg M^{\star \star}$ \\
\hline \multicolumn{5}{|l|}{ Maranhão } \\
\hline Urubú-Kaapór I & 160 & 15,6 & 0,0 & \\
\hline Urubú-Kaapór II & 47 & 80,8 & 0,0 & \\
\hline Awa-Guajá & 86 & 90,7 & 2,6 & 0 \\
\hline \multicolumn{5}{|l|}{ Amapá } \\
\hline Galibí-Uaçá & 159 & 32,1 & 2,0 & 1 \\
\hline Palikúr & 58 & 31,0 & 0,0 & \\
\hline Waiãpi & 89 & 47,2 & 4,8 & 2 \\
\hline \multicolumn{5}{|l|}{ Pará } \\
\hline Wayána-Apalaí I & 134 & 23,9 & 0,0 & \\
\hline Wayána-Apalaí II & 40 & 70,0 & 0,0 & \\
\hline Tiriyó & 26 & 11,5 & 33,3 & 1 \\
\hline Asuriní Kuatinemo & 41 & 61,0 & 8,0 & 1 \\
\hline Asuriní do Trocará & 21 & 14,3 & 0,0 & \\
\hline Arára Iriri & 28 & 0,0 & 0,0 & \\
\hline $\begin{array}{l}\text { Arára Laranjal/ } \\
\text { Kurambê }\end{array}$ & 47 & 27,7 & 7,7 & 0 \\
\hline Araweté & 81 & 25,9 & 4,8 & 1 \\
\hline Parakanã & 42 & 81,0 & 11,8 & 2 \\
\hline Aukre & 16 & 62,5 & 0,0 & \\
\hline Kubenkokre & 91 & 75,8 & 13,0 & 2 \\
\hline Pukany & 50 & 78,0 & 7,7 & 3 \\
\hline Kikretum & 16 & 50,0 & 0,0 & \\
\hline Kokraimôro & 93 & 55,9 & 3,8 & 1 \\
\hline Kararaô & 32 & 71,0 & 0,0 & \\
\hline Xikrín-Bacajá & 54 & 81,5 & 9,1 & 0 \\
\hline Mundurukú & 147 & 20,4 & 3,3 & 0 \\
\hline Katwena & 177 & 84,2 & 0,0 & \\
\hline \multicolumn{5}{|l|}{ Roraima } \\
\hline Yanomámi & 81 & 87,6 & 36,6 & 11 \\
\hline \multicolumn{5}{|l|}{ Amazonas } \\
\hline Yamamadí & 36 & 86,1 & 0,0 & \\
\hline \multicolumn{5}{|l|}{ Rondônia } \\
\hline Cinta-Larga & 102 & 47,1 & 6,2 & 0 \\
\hline Suruí & 59 & 20,3 & 0,0 & \\
\hline Karitiána & 73 & 21,9 & 0,0 & \\
\hline Total & 2.086 & 48,6 & 6,1 & 24 \\
\hline
\end{tabular}

* Percentual calculado sobre o número de positivos.

** Número absoluto de soros com a presença de IgM específica para Chlamydia. 
os Urubú-Kaapór $(15,6 \%$, na primeira visita em 1984), os Suruí (20,3\%) e os Mundurukú (20,4\%) - até atingir índices de prevalência altas - como nas tribos Urubú-Kaapór $(80,8 \%$, na revisita em 1994), Parakanã (81,0\%), Xikrín do Bacajá $(81,5 \%)$, Katwena $(84,2 \%)$, Yamamadí $(86,1 \%)$, Yanomámi (87,6\%) e Awa-Guajá (90,7\%). Quatorze comunidades mostraram prevalências de anticorpos de até $50 \%$, ao passo que seis apresentaram prevalências de até $70 \%$ e nove, prevalências maiores do que $70 \%$.

As primeiras visitas aos Urubú-Kaapór e aos Wayána-Apalaí mostraram exposição em níveis baixos (15,6\% e 23,9\%, respectivamente) para a Chlamydia; entretanto, as revisitas aos dois grupos evidenciaram marcante exposição e disseminação da bactéria entre ambos $(80,8 \%$ e $70,0 \%$, respectivamente).

Aparentemente, não ocorreu qualquer evidência de predominância da prevalência em relação à distribuição geográfica. As comunidades indígenas dos seis estados da Amazônia brasileira exibiram percentuais de prevalência baixos, médios e altos, indistintamente.

As amostras positivas foram tituladas com o objetivo de averiguar o percentual daquelas que apresentavam títulos de IgG $\geq 512$, de modo a indicar o nível de persistência da bactéria entre as comunidades testadas (Tabela 2). Vários grupos não mostraram títulos elevados de IgG para Chlamydia, porém a variação de prevalência entre os positivos foi extensa e ficou entre 2,0\% (Galibí-Uaçá) e 36,6\% (Yanomámi).

Os indivíduos com títulos elevados de anticorpos foram testados para a presença de anticorpos da classe IgM com a finalidade de diferenciar as infecções persistentes (aquelas com títulos elevados) daquelas infecções recentes (presença de IgM). Dentre as amostras testadas, 38,7\% (24/620) manifestaram anticorpos da classe IgM. Em 6,1\% (38/620), a bactéria estava em persistência no momento de obtenção da amostra.

Em quinze dentre as dezesseis comunidades indígenas foi possível constatar a presença de anticorpos para Chlamydia em crianças e adolescentes (faixa etária de 0-15 anos), que variou de 2,9\% entre os Urubú-Kaapór até $100 \%$ entre os Yamamadí (em ambos, na faixa etária de até 10 anos de idade). Entre os Asuriní do Trocará, a presença de anticorpos para Chlamydia só pôde ser mostrada entre indivíduos maiores de vinte anos (informações não mostradas).

A reatividade aos sorotipos da C. trachomatis e à C. pneumoniae foi determinada pelo uso da reação de MIF. A Tabela 3 mostra detalhadamente as reações dos indivíduos positivos a quinze sorotipos da $C$. trachomatis e ao antígeno de C. pneumoniae por meio da MIF. Foi possível descrever reações individuais, isoladas, para os sorotipos A, B, B , D, E, G, H, I e L $\mathrm{L}_{1}$. Reações sorológicas a múltiplos antígenos, incluindo-se aqueles em que não se evidenciou reações isoladas (sorotipos $\mathrm{C}, \mathrm{F}, \mathrm{L}_{2}$ e $\mathrm{L}_{3}$ ), foram comprovadas em várias ocasiões, completando, assim, o espectro de reatividade aos quinze sorotipos de C. trachomatis.

A Tabela 4 expõe, de maneira resumida, a ocorrência das reações sorológicas isoladas e múltiplas às duas espécies de Chlamydia na MIF. A maior freqüência de reações para a $C$. pneumoniae do que para a C. trachomatis $(p=0,0012)$ ficou patente. Em 12 (10,8 \%) das amostras não ocorreram reações para nenhum dos antígenos empregados.

A Tabela 5 exibe as maneiras diferentes como Chlamydia interage dentro das comunidades indígenas. Por meio da utilização dos índices de prevalência de anticorpos para Chlamydia e da associação com os níveis elevados de anticorpos IgG, determinados pela IFI, tornase possível mostrar que nem sempre ocorre padrão diretamente proporcional entre a exposição à bactéria e a persistência após a infecção. Foram detectados oito padrões de combinação entre os níveis de exposição e os níveis de persistência.

\section{Discussão}

O presente trabalho é o primeiro estudo soroepidemiológico efetuado com o intuito de conhecer a epidemiologia descritiva das bactérias do gênero Chlamydia - em particular as espécies C. trachomatis e a C. pneumoniae entre comunidades indígenas residentes em seis dos nove estados da Amazônia brasileira, distribuídos em uma abrangência de mais de $3.000 .000 \mathrm{~km}^{2}$.

A utilização de método sorológico para a detecção de anticorpos de longa duração tornou possível comprovar grande variabilidade de exposição associada à larga disseminação da Chlamydia nos grupos testados. Para melhor compreensão, os grupos foram divididos de acordo com a prevalência e a distribuição geográfica, como a seguir: (a) ausência de exposição à Chlamydia: Arára do Iriri (Pará); (b) prevalências entre $10 \%$ e $30 \%$ : Urubú-Kaapór I (Maranhão), Galibí e Palikúr (Amapá), WayánaApalaí I, Tiriyó, Asuriní do Trocará, Arára do Laranjal/Kurambê, Araweté e Mundurukú (Pará), Suruí e Karitiána (Rondônia); (c) prevalência entre 50\% e 70\%: Wayána-Apalaí II, Asuriní do 
Reatividade aos sorotipos de C. trachomatis e C. pneumoniae, por meio da MIF, em comunidades indígenas.

\begin{tabular}{|c|c|c|c|c|c|c|c|c|c|c|c|c|c|c|c|c|c|c|}
\hline População & $\mathrm{n} / \mathrm{Ta}^{\mathrm{a}}$ & $C p b$ & $A^{c}$ & B & $\mathrm{Ba}$ & C & D & $E$ & $F$ & G & $\mathrm{H}$ & 1 & $J$ & K & L1 & L2 & L3 & $N R^{f}$ \\
\hline Urubú-Kaapór I & $3 / 25$ & $2^{d}$ & & & & $/ 1$ & & & & 1 & & & & & $/ 1$ & & $/ 1$ & \\
\hline Urubú-Kaapór II & $5 / 38$ & 5 & & 1 & & & & & & & & & & & & & & \\
\hline Awa-Guajá & $17 / 78$ & 9 & $/ 1$ & & $/ 1$ & 12 & $d 1 / 2 e$ & & & 13 & $/ 2$ & & & $/ 2$ & 13 & & & 5 \\
\hline Galibí & $6 / 51$ & 6 & & $/ 1$ & & & $/ 1$ & & & 13 & $/ 3$ & & & $/ 1$ & 1 & & & \\
\hline Palikúr & $1 / 18$ & 1 & & & & & & & & & & & & $/ 2$ & & & & \\
\hline Waiãpi & $2 / 42$ & 2 & & & & 12 & & & & & & & & 12 & & & & \\
\hline Wayána-Apalaí I & $4 / 32$ & 2 & 1 & & & & & & & & & & & & & & & 2 \\
\hline Wayána-Apalaí II & $4 / 28$ & 4 & & & & & & & & 2 & 1 & & & & & & & \\
\hline Tiriyó & $1 / 3$ & 1 & & & & & & & & & 1 & & & & & & & \\
\hline Asuriní Kuatinemo & $3 / 25$ & & & & & & & & & & 1 & & & & & & & 2 \\
\hline Asuriní do Trocará & $1 / 3$ & & & & & & & & & & & & & & & & & 1 \\
\hline Araweté & $3 / 21$ & 3 & & & & & & & & & $/ 1$ & & $/ 1$ & $/ 1$ & $/ 1$ & & & \\
\hline Parakanã & $5 / 34$ & 3 & & & & 13 & & $/ 1$ & & & 12 & 12 & & 13 & $/ 1$ & & & \\
\hline Aukre & $1 / 10$ & 1 & & & & & & & & & & & & & & & & \\
\hline Pukany & $2 / 39$ & 2 & & & 1 & & & $/ 1$ & & & & & $/ 1$ & $/ 1$ & & & & \\
\hline Kokraimôro & $4 / 52$ & 2 & $/ 1$ & $/ 1$ & & $/ 1$ & 12 & & & 13 & 12 & $/ 1$ & & & & & & 1 \\
\hline Kararaô & $4 / 23$ & 4 & & & & & & & & & & 11 & & & & & 11 & \\
\hline Xikrín-Bacajá & $5 / 44$ & 4 & & 12 & 12 & $/ 1$ & $/ 1$ & $/ 1$ & & $1 / 1$ & $1 / 1$ & $/ 2$ & & $/ 1$ & $/ 1$ & $/ 1$ & & \\
\hline Mundurukú & $1 / 30$ & 1 & & & & & & & & & & & & & & & & \\
\hline Katwena & 20/149 & 20 & & & & & 12 & & & $4 / 1$ & $6 / 1$ & $/ 1$ & $/ 1$ & $/ 1$ & $/ 1$ & $/ 1$ & $/ 2$ & \\
\hline Yanomámi & $10 / 71$ & 4 & & & & & 2 & & & & $/ 1$ & 1 & & & $4 / 1$ & & & \\
\hline Yamamadí & $2 / 31$ & 2 & & & $/ 1$ & & & & & $/ 1$ & $1 / 1$ & & & & & & & \\
\hline Cinta-Larga & $4 / 48$ & 1 & & & & & & & & & $1 / 1$ & & & & $/ 2$ & & 12 & 1 \\
\hline Suruí & $2 / 12$ & 2 & & & & & & & & & & & & $/ 1$ & $/ 1$ & & & \\
\hline Karitiána & $1 / 16$ & 1 & & & & & & & & & 1 & & & & & & & \\
\hline Total & $111 / 923$ & 82 & $1 / 2$ & $1 / 4$ & $1 / 4$ & $/ 10$ & $3 / 8$ & $1 / 2$ & 0 & $8 / 12$ & $13 / 15$ & $1 / 7$ & 13 & $/ 13$ & $5 / 12$ & 12 & 16 & 12 \\
\hline
\end{tabular}

a número de amostras testadas (MIF)/total de amostras positivas (IFI) do grupo populacional em questão

b C. pneumoniae

c sorotipos de $C$. trachomatis $\left(A\right.$ à $\left.L_{3}\right)$

d número de amostras que apresentaram reação sorológica a um único sorotipo de Chlamydia

e número de amostras que apresentaram reação sorológica a múltiplos sorotipos de $C$. trachomatis

f amostras positivas pela reação de IFI, que não reagiram na MIF

Kuatinemo, Aukre, Kikretum, Kokraimôro e Kararaô (Pará); (d) prevalências entre $70 \%$ e $80 \%$ : Urubú-Kaapór II (Maranhão), Kubenkokre e Pukany (Pará); (e) prevalências acima de $80 \%$ : Parakanã, Xikrín e Katwena (Pará), Yanomámi (Roraima) e Yamamadí (Amazonas).

A alta taxa de transmissão da Chlamydia em pequenas comunidades indígenas é preocupante, uma vez que seus hábitos culturais favorecem a disseminação de patógenos transmitidos usualmente pela via sexual, incluindo o Treponema e o herpes simples do tipo 2 por outras vias (Black et al., 1974; Lee et al., 1978). É situação grave, em razão de já se ter detectado, em algumas dessas comunidades indígenas, outros marcadores de infecções sexualmente transmissíveis, incluindo-se reatividade ao VDRL, persistência do vírus da hepatite B e lesões por herpes simples, (Ishak et al., 1993; Santos et al., 1995), afora a Neisseria em crianças com menos de dez anos de idade que apresentavam corrimento vaginal.

As prevalências de anticorpos IgG para Chlamydia nas tribos Urubú-Kaapór (15,6\% e 80,8\%) e Wayána-Apalaí (23,9\% e 70\%) demonstram, de maneira clara, o aumento da disseminação das espécies da bactéria em intervalo de tempo de dez anos, decorrente da intensificação do contato da comunidade indígena com comunidades de neo brasileiros. Em estudo anterior feito em nosso laboratório, já havia sido possível demonstrar a ausência do vírus da hepatite B na comunidade dos Parakanã mediante coleta de soro efetuada em 1983, próximo do primeiro contato do grupo (Santos et al., 1995), e a introdução do vírus, mais tarde, em 
decorrência dos contatos subsequentes (Vieira Filho et al., 1990).

A disseminação de infecções sexualmente transmissíveis nessas comunidades deve ser considerada como verdadeira ameaça a sua perpetuação em virtude do risco de infertilidade que pode vir associado a essas infecções. As informações de prevalência de anticorpos para o gênero Chlamydia refletem o espectro total da exposição às espécies da bactéria, sem implicar exposição àquelas que são causas comuns de doença genital. Contudo, a descrição dos sorotipos de C. trachomatis circulantes entre as comunidades indígenas (Tabela 3) mostra, com nitidez, que essas populações estão expostas também a sorotipos associados comumente à transmissão pela via sexual. Os so-

Tabela 4

Resumo da reatividade aos sorotipos de C. trachomatis e C. pneumoniae, por meio do MIF, em comunidades indígenas da Amazônia brasileira.

\begin{tabular}{lc}
\hline Reatividade & Número Examinado \\
\hline Somente à Chlamydia trachomatis & 16 \\
Somente à Chlamydia pneumoniae & 35 \\
A ambas as espécies & 48 \\
Ausência de reatividade & 12 \\
Total & 111 \\
\hline
\end{tabular}

rotipos $\mathrm{H}, \mathrm{G}$ e $\mathrm{L}_{1}$ foram os evidenciados mais freqüentemente pela MIF, em contrapartida aos sorotipos D, E e F observados em outros países (Poole \& Lamont, 1992).

Títulos elevados de anticorpos IgG para Chlamydia sugerem a presença de infecções recentes e/ou persistentes. Em mulheres com infecções cervicais não complicadas, os títulos situam-se usualmente entre 64 e 128, enquanto que os títulos de IgG são consideravelmente mais altos naquelas com DIP (Darougar et al., 1983).

Pela primeira vez em nossa região e, talvez, em nosso país, os títulos elevados $(\geq 512)$ de anticorpos para Chlamydia, na ausência de IgM encontrados em $6,1 \%$ dos indivíduos testados no presente trabalho (Tabela 2) -, indicam tendência do percentual das pessoas que após a infecção permanecem disseminando o patógeno, provavelmente, sem manifestações clínicas aparentes.

Não existem evidências de indicativos de cálculos acerca da persistência da Chlamydia na literatura pertinente, pelas quais se possa estabelecer comparação com os resultados divulgados no presente trabalho. Mais recentemente, com o uso de técnicas de amplificação de ácidos nucléicos, tem sido possível mostrar níveis variáveis (de 6,5\% até 17,5\%) da ocorrência da C. trachomatis em mulheres com infecções genitais assintomáticas (Lan et al., 1995; Cheema et al., 2000). A persistência da C. trachomatis em mulheres assintomáticas leva-nos

Variabilidade na exposição e persistência (por meio da detecção e titulação dos níveis de anticorpos IgG, por meio da (FI) das espécies de Chlamydia em comunidades indígenas da Amazônia brasileira.

\begin{tabular}{|c|c|c|c|c|}
\hline $\begin{array}{l}\text { Nível de } \\
\text { Exposição* }\end{array}$ & $\begin{array}{l}\text { Nível de } \\
\text { Persistência** }\end{array}$ & Comunidade Indígena & Exposição (\%) & Persistência (\%) \\
\hline Baixo & Baixo & Mundurukú & 20,4 & 3,3 \\
\hline Baixo & Médio & Arára Laranjal/Kurambê & 27,7 & 7,0 \\
\hline Baixo & Alto & Tiriyó & 11,5 & 33,3 \\
\hline \multirow[t]{2}{*}{ Médio } & Baixo & Kokraimôro & 55,9 & 1,9 \\
\hline & & Asuriní do Kuatinemo & 61,0 & 4,0 \\
\hline Médio & Médio & Cinta-Larga & 47,1 & 6,2 \\
\hline Alto & Baixo & Awa-Guajá & 90,7 & 2,6 \\
\hline \multirow[t]{2}{*}{ Alto } & Médio & Parakanã & 81,0 & 5,9 \\
\hline & & Xikrín & 81,5 & 9,5 \\
\hline \multirow[t]{2}{*}{ Alto } & Alto & Kubenkokrê & 75,8 & 10,1 \\
\hline & & Yanomámi & 87,6 & 21,1 \\
\hline
\end{tabular}

* Nível de exposição: medido pela prevalência de anticorpos para Chlamydia e considerado baixo (<30\%) médio $(<70 \%)$ e alto ( $>70 \%)$.

** Nível de persistência: medido pelo percentual de indivíduos com títulos elevados de lgG e considerado baixo $(<5 \%)$, médio $(<10 \%)$ e alto $(>10 \%)$. 
a perguntar se essas mulheres podem vir a apresentar complicações como DIP e infertilidade, dentre outras (Lan et al., 1995).

Entre as comunidades indígenas é provável que haja um ou mais fatores de natureza genética que contribuam para modular a maneira como a Chlamydia interage com o hospedeiro humano indígena da Amazônia brasileira no processo de multiplicação e, consequentemente, na causa da doença. As comunidades indígenas têm mostrado nível baixo de variabilidade genética quando se considera o perfil convencional de marcadores genéticos (Salzano \& Calegari-Jaques, 1988) e esta baixa variabilidade genética tem sido sugerida como uma das razões para a maior ou menor susceptibilidade a doenças infecciosas, de maneira geral, entre comunidades indígenas (Black, 1992).

Uma das evidências da diferença de como a Chlamydia interage com o hospedeiro pode ser encontrada na prevalência elevada de anticorpos entre os Urubú-Kaapór (80,8\%), os Wayána-Apalaí $(70,0 \%)$, os Katwena $(84,2 \%)$ e os Yamamadí $(86,1 \%)$, sem que ocorra persistência bacteriana nas populações examinadas. Esse tipo de interação aconteceu também entre comunidades em que houve baixa exposição à Chlamydia, como nos Palikúr (31,0\%), Asuriní do Trocará (14,3\%), nos Suruí (20,3\%) e Karitiána $(21,9 \%)$. Em contraposição, é possível encontrar comunidades com níveis variáveis de exposição e níveis baixo $(<5 \%)$, médio ( $5 \%$ a $10 \%$ ) e alto ( $>10 \%$ ) de persistência, como descrito na Tabela 5.

Esse tipo de observação havia sido efetuada anteriormente por nosso laboratório, usando o vírus da hepatite B como modelo da possível influência do perfil genético de populações indígenas na modulação da persistência do vírus (Santos et al., 1995), e é provável que outros agentes infecciosos sejam influenciados de maneira semelhante em seu processo de infecção e doença.

Com o intuito de avaliar e descrever a ocorrência dos sorotipos de C. trachomatis e a de $C$. pneumoniae, foi efetuada amostragem randômica utilizando-se programa de computação (Epi Info, versão 6.0 - CDC/WHO, 1996). Foram selecionadas $12 \%$ das amostras positivas (111/ 923) para serem testadas pela MIF. Reações isoladas para os sorotipos A, B, B, D, E, G, H, I e $\mathrm{L}_{1}$ foram descritas, excetuando-se unicamente para o sorotipo $\mathrm{F}$.

Os sorotipos A, B, B $\mathrm{a}$ e C estão relacionados às áreas onde o tracoma é endêmico, porém o sorotipo A é reconhecido por apresentar distribuição geográfica limitada ao Oriente Médio e Norte da África, enquanto os sorotipos B e C são cosmopolitas e o $\mathrm{B}_{\mathrm{a}}$, endêmico entre índios Americanos (Grayston \& Wang, 1975). Pela primeira vez, a reatividade ao sorotipo A é descrita em outra região fora de sua distribuição caracteristicamente restrita ao Oriente Médio e África. As reações foram encontradas entre os Awa-Guajá, os Wayána-Apalaí e os Kokraimôro.

As observações clínico-epidemiológicas relatadas por Freitas (1976) corroboram que a região Amazônica é endêmica para o tracoma, porém os casos clínicos podem estar passando sem ter diagnóstico clínico e laboratorial realizado de forma adequada. Nas visitas médicas efetuadas pelos grupos de trabalho não ocorreu nenhum fato que chamasse a atenção para qualquer doença ocular que pudesse lembrar o tracoma ou a conjuntivite. É de se esperar que a busca ativa dos mesmos, em expedições futuras, garanta o encontro de casos da doença.

A reação de MIF foi útil, precisa e específica para evidenciar - pela primeira vez em nosso país - que, além da C. trachomatis, há também a circulação da C. pneumoniae entre as populações indígenas que habitam a região Amazônica do Brasil. A metodologia utilizada permite que se observem reações específicas sem a interferência de reações cruzadas entre as espécies de Chlamydia (Grayston et al., 1989; Ozanne \& Lefebvre, 1992). A sua detecção aconteceu em quase todos os grupos testados, e é possível que os Asuriní do Kuatinemo e do Trocará representem duas comunidades que ainda não entraram em contato com o agente.

Acredita-se que a circulação da C. pneumoniae seja bem maior do que a da C. trachomatis, mas a média tem sido em torno de $50 \%$ de positividade entre adultos, ainda que seja possível atingir índices mais altos (>70\%), como, por exemplo, em Formosa e no Panamá (Grayston et al., 1989; Kuo et al., 1995). A prevalência entre países em desenvolvimento ainda não está completamente definida; entretanto, estima-se que a presença de anticorpos comece o seu aparecimento mais cedo do que nos países de clima temperado (Mahmoud et al., 1994). Na África do Sul e na Etiópia, a infecção por uma das espécies de Chlamydia é usualmente predominante, o que indica a influência do comportamento humano e de fatores ambientais na disseminação das bactérias (Mahmoud et al., 1994).

O presente trabalho é a primeira abordagem com a finalidade de determinar a presença desse agente infeccioso no Brasil e utilizou desenho experimental soroepidemiológico retrospectivo, mostrando a reatividade por meio da MIF para a bactéria. A C. pneumoniae, tem sido freqüentemente relatada como causa co- 
mum de infecções do trato respiratório inferior e, em particular, como uma das grandes causas de PAC. A evidência sorológica de infecção prévia pela $C$. trachomatis em grupo que habita área tão extensa, deixa a pergunta sobre qual é a implicação real desse agente infeccioso em relação à etiologia de doença, em especial, nesse ambiente epidemiológico. A C. pneumoniae é causa comum de doença respiratória grave e deve ser considerada prioridade quando se avalia a etiologia de patógenos no diagnóstico diferencial de infiltrados intersticiais (Clarck et al., 1991; Comandini et al. 1997).

É certamente esperado que a C. pneumoniae esteja causando doença entre os diversos grupos examinados, porém permanece sem adequado diagnóstico clínico e laboratorial e, em conseqüência, sem receber o benefício do tratamento conveniente. Tratamentos empíricos são sempre possíveis de ser estabelecidos em casos de infecções agudas do trato respiratório, como medida médica geral e imediata (Langtry \& Brogden, 1997). Espera-se que, com a expansão das associações da C. pneumoniae com quadros clínicos que incluem doença coronariana crônica, o diagnóstico laboratorial seja mais comumente efetuado e se torne mais acessível à população em geral.

Convém ressaltar que a C. pneumoniae também é capaz de permanecer em estado de persistência em macrófagos alveolares (Moazed et al., 1998), até mesmo após o uso de terapêutica em regime de dose única, o que o torna agente infeccioso capaz de atingir sucesso em sua disseminação (Campbell et al., 1998).

Dentre os 111 indivíduos testados para as duas espécies de Chlamydia, um total de 10,8\% dos soros que já haviam reagido por meio do teste de IFI, não mostraram resposta com as espécies testadas na reação de MIF. É possível que a reação primária esteja detectando anticorpos para o gênero Chlamydia, porém para uma espécie diferente daquelas testadas na MIF. Em habitantes de seis áreas indígenas distintas ocorreu essa falta de reatividade, indicando que se pode estar diante de reações com a C. psittaci ou outra espécie ainda não associada à infecção em seres humanos, como a $C$. pecorum.

Ainda que as reações evidenciadas na Tabela 5 não envolvam índice de prevalência já que foi feita apenas uma amostragem dentre os positivos, chamou a atenção o fato da maior ocorrência de reações para C. pneumoniae entre os indígenas do que as reações para a C. trachomatis em níveis estatisticamente significantes $(p=0,0012)$. Os anticorpos detectados no teste de IFI refletem o impacto do gênero Chlamydia nas comunidades estudadas, colaborando para o aparecimento de doenças debilitantes tanto no trato genitourinário como no trato respiratório, além das oculares.

As bactérias do gênero Chlamydia estão comumente listadas entre os agentes infecciosos emergentes e reemergentes de todos os países que mantém sistemas de vigilância epidemiológica, inclusive a sorovigilância (Walford \& Noah, 1999). Estima-se que a C. trachomatis seja hoje a maior causa bacteriana de doenças sexualmente transmissíveis, no entanto somente $10 \%$ dos casos são adequadamente identificados (Walford \& Noah, 1999).

O presente trabalho seguiu a trilha de um estudo de epidemiologia descritiva em vasto grupo populacional residente na Amazônia brasileira, com o intuito de iniciar o entendimento do impacto da Chlamydia. Particularmente nos dias atuais, em que tais agentes infecciosos emergem e reemergem, a epidemiologia descritiva volta a assumir papel primordial para o entendimento de tais processos (Barradas, 1997). A soroepidemiologia, tal como foi utilizada no presente trabalho, é certamente uma das ferramentas apropriadas para alcançar tal objetivo. A descrição da ocorrência de reações sorológicas específicas para a C. trachomatis e para a C. pneumoniae definem com precisão a amplitude da distribuição e disseminação de patógenos que podem causar doenças graves ao hospedeiro humano, mas que são freqüentemente passíveis de tratamento quando diagnosticadas adequadamente. 


\section{Agradecimentos}

Às comunidades indígenas examinadas. Aos colegas de trabalho S. E. Santos, J. F. Guerreiro, A. K. C. R. Santos, E. Santos, V. Monteiro, E. S. Abrahim, V. N. Azevedo, A. C. R. Vallinoto e S. Caniceiro. Este trabalho foi custeado pelo Programa Nacional de DST/AIDS do Ministério da Saúde, pelo Conselho Nacional de Desenvolvimento Científico e Tecnológico e pela Universidade Federal do Pará.

\section{Referências}

AYRES, M.; AYRES-J. R.; AYRES, D. L. M. \& SANTOS, A. S., 1998. BioEstat: Aplicações Estatísticas nas Áreas das Ciências Biológicas e Médicas. Manaus: Sociedade Civil Mamirauá.

BACHMAIER, K.; NEU, N.; DE LA MAZA, L. M.; PAL, S.; HESSEL, A. \& PENNINGER, J. M., 1999. Chlamydia infections and heart disease linked through antigenic mimicry. Science, 283:1335-1339.

BARRADAS, R. C. B., 1997. O desafio das doenças emergentes e a revalorização da epidemiologia descritiva. Revista de Saúde Pública, 31:531-537.

BLACK, F. L., 1992. Why did they die? Science, 258: 1739-1740.

BLACK, F. L.; HIERHOLZER, W. J.; PINHEIRO, F. P.; EVANS, A. S.; WOODWALL, J. P.; OPTON, E. M.; EMMONS, J. E.;WEST, B. S.; EDSALL, G.; DOWNS, W. G. \& WALLACE, G. D., 1974. Evidence for persistence of infectious agents in isolated human populations. American Journal of Epidemiology, 100:230-250.

CAMPBELL, L. A.; KUO, C. C. \& GRAYSTON, J. T., 1990. Structural and antigenic analysis of Chlamydia pneumoniae. Infection and Immunity, 58:93-97.

CAMPBELL, L. A.; KUO, C. C. \& GRAYSTON, J. T., 1998. Chlamydia pneumoniae and cardiovascular disease. Emerging Infectious Diseases, 4:571-579.

CDC (Centers for Disease Control and Prevention) WHO (World Health Organization), 1996. Epi Info 6, Version 6.04. A Word Processing, Database, and Statistics Program for Public Health. Atlanta: CDC/ Geneva: WHO.

CHEEMA, M. A.; RAHMAN, M. U.; WHITTEEM-HUDSON, J. A. \& HUDSON, A. P., 2000. Rapid communication: Cervical Chlamydia trachomatis in women at low risk for infection. American Journal of Medical Science, 319:123-125.

CLARK, R.; MUSHHATT, D. \& FAZAL, B., 1991. Case report: Chlamydia pneumoniae pneumonia in an HIV-infected man. American Journal of Medical Science, 302:155-156.

COLLIER, L. H.; SOWA, J. \& SOWA, S., 1972. The serum and conjunctival antibody response to trachoma in Gambian children. Journal of Hygiene, 72:727740 .
COMANDINI, U. V.; MAGGI, P.; SANTOPADRE, P.; MONNO, R.; ANGARANO, G. \& VULLO, V., 1997. Chlamydia pneumoniae respiratory infection among patients infected with the human immunodeficiency virus. European Journal of Clinical Microbiology, 16:720-726.

DAROUGAR, S.; ARAMESH, B.; GIBSON, J. A.; TREHARNE, J. D. \& JONES, B. R., 1983. Chlamydial genital infection in prostitutes in Iran. British Journal of Venereal Diseases, 59:53-55.

FREITAS, C. A., 1976. Prevalência do tracoma no Brasil. Revista Brasileira de Malariologia e Doenças Tropicais, 28: 227-233.

GRAYSTON, J. T.; KUO, C. C.; CAMPBELL, L. A. \& WANG, S. P., 1989. Chlamydia pneumoniae sp. nov. for Chlamydia sp. TWAR. International Journal of Systematic Bacteriology, 39:88-90.

GRAYSTON, J. T. \& WANG, S. P., 1975. New knowledge of chlamydiae and the diseases they cause. Journal of Infectious Diseases, 132:87-105.

ISHAK, M. O. G., 2000. O Impacto da Chlamydia em Populações Humanas da Amazônia Brasileira. Tese de Doutorado, Belém: Centro de Ciências Biológicas, Universidade Federal do Pará.

ISHAK, M. O. G.; ISHAK, R.; CRUZ, A. C.; SANTOS, D. E. \& SALGADO, U., 1993. Chlamydial infection in the Amazon region of Brazil. Transactions of the Royal Society of Tropical Medicine and Hygiene, 87:60-62.

ISHAK, M. O. G.; MUMTAZ, G.; ISHAK, R. \& RIDGWAY, G. L., 1988. Prevalence of antibodies to Chlamydia trachomatis in population groups of Brazil, England and Portugal. Revista do Instituto de Medicina Tropical de São Paulo, 30:40-44.

KUO, C. C.; JACKSON, L. A.; CAMPBELL, L. A. \& GRAYSTON, J. T., 1995. Chlamydia pneumoniae (TWAR). Clinical Microbiology Reviews, 8:451-461.

LAN, J.; MELGERS, I.; MEIJER, C. J. L. M.; WALBOONERS, J. M. M.; ROOSENDAAL, R.; BURGER, C. \& BLEKER, O. P., 1995. Prevalence and serovar distribution of asymptomatic cervical Chlamydia trachomatis infections as determined by highly sensitive PCR. Journal of Clinical Microbiology, 33:3194-3197. 
LANGTRY, H. D. \& BROGDEN, R. N., 1997. Clarythromycin. A review of its efficacy in the treatment of respiratory tract infections in immunocompetent patients. Drugs, 53:973-1004.

LEE, R. V.; BLACK, F. L.; HIERHOLZER. W. J. \& WEST, B. S., 1978. A novel pattern of treponemal antibody distribution in isolated South American Indian populations. American Journal of Epidemiology, 107:46-53.

MAGALHÃES, M.; ANDRADE, M. \& VERAS, A., 1982. Uretrites não gonocócicas masculinas associadas a Chlamydia, Ureaplasma e Trichomonas. Revista de Microbiologia, 13:156-160.

MAHMOUD, E.; ELSHIBLY, S. \& MARDH, P. A., 1994. Seroepidemiologic study of Chlamydia pneumoniae and other chlamydial species in a hiperendemic area for trachoma in the Sudam. American Journal of Tropical Medicine and Hygiene, 51: 489-494.

MAUSNER, J. S. \& BAHN, A. K., 1974. Epidemiology: An Introductory Text. Philadelphia: W. B. Saunders Company.

MOAZED, T. C.; KUO, C. C.; GRAYSTON, J. T. \& CAMPBELL, L. A., 1998. Evidence of systemic dissemination of Chlamydia pneumoniae infection via macrophages in the mouse. Journal of Infectious Diseases, 177:1322-1325.

OZANNE, G. \& LEFEBVRE, J., 1992. Specificity of the microimmunofluorescence assay for the diagnosis of Chlamydia pneumoniae infections. Canadian Journal of Microbiology, 88:1185-1189.

PEELING, W. \& BRUNHAM, R. C., 1996. Chlamydiae as pathogens: New species and new issues. Emerging Infectious Diseases, 2:1-16.

POOLE, E. \& LAMONT, I., 1992. Chlamydia trachomatis serovar differentiation by direct sequence analysis of the variable segment 4 region of the major outer membrane protein gene. Infection and Immunity, 60:1089-1094.
QUINN, T. C.; GAYDOS, C.; SHEPHERD, M.; BOBO, L.; HOOK, III E. W.; VISCIDI, R.; ROMPALO, A., 1996. Epidemiologic and microbiologic correlates of Chlamydia trachomatis infection in sexual partnerships. JAMA, 276:1737-1742.

RICHMOND, S. J. \& CAUL, E. O., 1975. Fluorescent antibody study in chlamydiae infection. Journal of Clinical Microbiology, 1:345-352.

SALZANO, F. M. \& CALLEGARI-JACQUES, S. M., 1988. South American Indians. A Case Study in Evolution. Oxford: Claredon Press.

SANTOS, A. K. C. R.; ISHAK, M. O. G.; SANTOS, S. E. B.; GUERREIRO, J. F. \& ISHAK, R., 1995. A possible correlation between the host genetic background in the epidemiology of Hepatitis B virus in the Amazon region of Brazil. Memórias do Instituto Oswaldo Cruz, 90:435-441.

TREHARNE, J. D.; DAROUGAR, S. \& JONES, B. R., 1977. Modification of the microimmunofluorescence test to provide a routine serodiagnostic test for chlamydial infection. Journal of Clinical Pathology, 30:510-517.

VIEIRA FILHO, J. B.; CRUZ, C. F. N.; KEMP, L.; SANTOS, O. M. \& GUIMARÃES, R. X., 1990. Prevalência dos marcadores sorológicos do HBV em indígenas do Sudeste do Pará (PA). GED, 9:35-36.

WALFORD, D. \& NOAH, N., 1999. Emerging infectious diseases-United Kingdom. Emerging Infectious Diseases, 5:1-6.

WANG, S. P. \& GRAYSTON, J. T., 1974. Human serology in Chlamydia trachomatis infection with microimmunofluorescence. Journal of Infectious Diseases, 130:388-397.

WASHINGTON, A.; JOHNSON, R. E. \& SANDERS, L., Jr., 1987. Chlamydia trachomatis infection in the United States: What are they costing us? JAMA, 257:2070-2072.

WHO (World Health Organization), 1995. Sexually Transmitted Diseases. WHO Technical Report 64. Geneva: WHO. 